
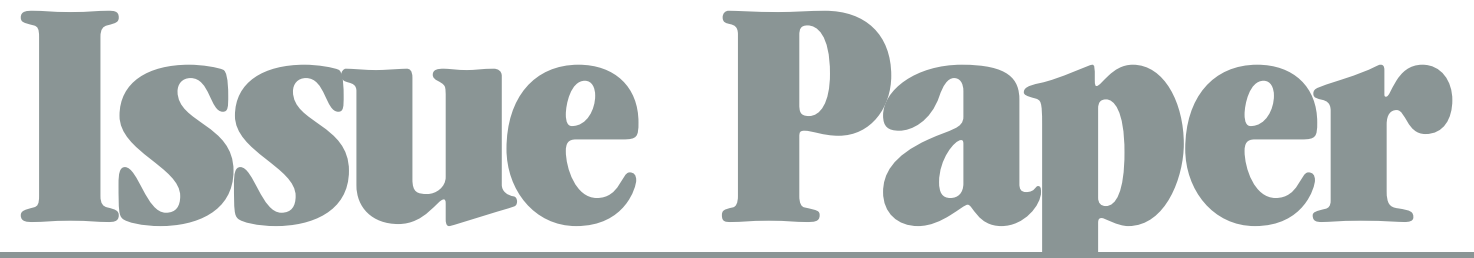

\title{
RAND
}

\section{Approaches to Making Military-Civilian Domestic Violence Collaborations Work Lessons Learned from Two Case Studies}

\author{
Laura J. Hickman, Lois M. Davis, and Paul Steinberg
}

\section{INTRODUCTION}

Between 2000 and 2003, the Defense Task Force on Domestic Violence (DTFDV), created by the Department of Defense (DoD), conducted a comprehensive review examining official domestic violence (DV) policies and DV practices at select military installations. The DTFDV submitted its findings in three annual reports in 2001, 2002, and 2003 and made a total of 168 recommendations for improvement, of which the DoD agreed to implement 116 and give further study to 19 . A DoD response has not yet been provided to 13 recommendations. ${ }^{1}$

While the recommendations span a wide range of DV issues in the military, a small subset of those recommendations focuses on concerns surrounding the need for collaboration between military and civilian authorities on DV cases involving service members that occur in the civilian community and on DV cases occurring on military installations. ${ }^{2}$

Although military installations are separated from surrounding communities in a number of ways, military installations are not islands. Service members and their families regularly visit surrounding communities, and many live off the installation among the civilian population. Any domestic violence that occurs off installations is under the jurisdiction of local civilian authorities.

However, civilian and military authorities could make an agreement whereby an incident in which the alleged offender is an active-duty personnel may be handled through the military justice system rather than the civilian justice system.

Civilian authorities may also have jurisdiction (and may be first responders) over incidents that occur on

\section{Military Installation Jurisdiction}

Four types of jurisdiction are relevant to civilian involvement in DV on military installations: 4

- Exclusive Federal Jurisdiction. The federal government holds all authority, and civilian authorities have essentially no power. All offenses, including DV, are handled only by the military or other elements of the federal justice system. For offenses or actions that have taken place off the installation, civilian authorities have the "right to serve process" or present legal papers, such as arrest warrants, subpoenas, civil orders, and civil process papers, but they can only enter the installation with military approval.

- Concurrent Jurisdiction. Both state and federal governments share authority over the area and either may be the first responder and may prosecute offenses. These arrangements vary and depend on state and local agreements between civilian and installation authorities.

- Partial Jurisdiction. States give the federal government authority in some areas of law but reserve the authority over others. States vary as to which powers are reserved.

- Proprietary-Interest Jurisdiction. Except as specified by the U.S. Constitution, the federal government does not have jurisdiction, and all legal authority is maintained by the state.

RAND issue papers explore topics of interest to the policymaking community. Although issue papers are formally reviewed, authors have substantial latitude to express provocative views without doing full justice to other perspectives. The views and conclusions expressed in issue papers are those of the authors and do not necessarily represent those of RAND or its research sponsors.

(c) Copyright RAND 2003. 
installations. The traditional conception of a military installation is that of an area under complete federal control, but this is the exception rather than the rule. Although neither the DoD nor the individual services appear to maintain records of jurisdiction type, 3 a DoD-sponsored 1986 study found that only 141 (16 percent) of the 874 U.S.-based Army, Marine, Navy, and Air Force installations were under exclusive federal jurisdiction. It also found that the majority (87 percent) of U.S.-based service members and their families were stationed at the 733 installations that fall under shared or complete civilian jurisdiction. 5 A number of bases have been closed since this study was undertaken but we could find no more recent data.

The fact that service members often live in civilian communities and that most U.S.-based installations fall

\section{Case Study Methodology}

The case studies were conducted in two localities-Anchorage, Alaska and San Diego, California. These two localities were the first recipients of funds from the DoD under an incentive program intended to promote DV collaborations between installations and surrounding communities. 6 We selected the two locations because both already had some level of military-civilian collaboration prior to receiving the DoD grant but had been working on forming new types of relationships and enhancing existing relationships over the one-year grant period, which ended in June 2003. San Diego represents a community with a longer history of building collaboration (nearly 10 years) compared with more-recent efforts in Anchorage (around three years). Moreover, between these two locations, installations for the four military services-Army, Marines, Navy, and Air Force-are represented. In both areas, the number of active-duty members stationed at the neighboring installations is equal to about 4 percent of the city population. 7

\section{DoD Incentive Grants}

The two military installations that neighbor Anchorage, AlaskaElmendorf Air Force Base and the Army's Fort Richardson-applied and received funds for forming DV collaborative relationships with civilian agencies within the city of Anchorage. The project, entitled "Joining Forces: A Coordinated Community Response to Domestic Violence," sponsored a series of joint training sessions; a three-day conference featuring presentations by both civilian and military representatives; and the development of a Web site for posting community and military information and resources.

In the San Diego area, the three neighboring military installations-Navy Region Southwest, Marine Corps Recruit Depot, and Marine Corps Air Station Miramar - were awarded funds to sponsor the addition of a military liaison position to San Diego's Family Justice Center. The Family Justice Center is a single location in San Diego intended to serve as "one-stop shopping" for DV victims. It houses 24 different agencies that provide services to DV victims, including police, prosecutors, victim advocates, and civil attorneys. This military liaison position was structured to serve as (1) a source of referral information for victims - service members or intimate partners of service members identified through the San Diego Police Department Domestic Violence Unit-and (2) a bridge between civilian agencies and military installations for addressing domestic violence involving service members.

\section{Case Study Interviews}

Whereas the DTFDV case studies included site visits with and inter- under shared or complete civilian authority illustrates why the DTFDV called for military-civilian collaboration. Because both civilian and military authorities play a role in responding to DV incidents involving service members, the DoD has agreed to take steps to promote collaborative relationships. To be successful in forming these relationships, however, civilian communities and local installations are likely to face a variety of challenges.

This issue paper presents findings from case studies in two localities-Anchorage, Alaska and San Diego, California-undertaken to gather preliminary information about military-civilian DV collaborations. Since we conducted only two limited case studies, the findings discussed here are by no means intended to be representative or comprehensive. They can, however, suggest the unique

views of military personnel, our case studies consisted of key informant interviews within both civilian communities and neighboring military installations. Four interviews were conducted by telephone, but the vast majority of interviews was conducted in person during local site visits. We also attended one of the monthly meetings of the multiagency DV planning body or DV council in each city. ${ }^{8}$ Representatives from the neighboring installations have formal, participating roles in both bodies.

In San Diego, we conducted interviews with representatives of the San Diego Police Department (SDPD) Domestic Violence Unit and staff from the San Diego City Attorney's Office. At the neighboring military installations, we interviewed representatives from the Navy's Staff Judge Advocate's Office, staff in management positions responsible for Navy and Marine programs that include the Family Advocacy Program (FAP) at Navy Region Southwest and Marine Corps Air Station Miramar. ${ }^{9}$ At the Marine Corps Recruit Depot, we interviewed staff holding a management position in the installation's FAP. We also interviewed a military law enforcement officer involved with the court liaison program for Navy Region Southwest and a physician at the Naval Medical Center. Finally, we interviewed the individual holding the military liaison position created through the DoD incentive grant.

In the Anchorage civilian community, we interviewed representatives of three victim services organizations, as well as representatives of three DV intervention programs and a nonprofit organization that provides legal services to low-income victims of DV. We also interviewed representatives of the Anchorage Police Department (APD), Alaska State Troopers, Municipal Prosecutor's Office, and the Anchorage District Court. At Elmendorf Air Force Base, we interviewed representatives of the FAP and a high-level commander. At Fort Richardson, we interviewed a representative from the installation's FAP, a representative of the military police, a victim advocate, and a high-level commander. We provided all interviewees with confidentiality assurance indicating that we would not disclose their identities or use quotes from them without their permission.

For all interviewees, we used a semi-structured interview protocol that covered a range of topics specifically developed for each agency and position type, including individual roles in working with DV issues, general DV policy environment, prior history of collaboration and current experience with collaboration, challenges encountered in forming collaborative relationships, and areas for improvement and suggestions for forming collaborations in other locations. 
challenges of implementing military-civilian DV collaborations and some strategies to overcome them that might be tested in other areas.

The sidebar on page 2 presents a brief discussion of the two case study sites and the methodology used; below we present the lessons learned, along with suggestions for improving DV collaboration. We close with a discussion of further research needed in the area of DV collaboration.

\section{LESSONS LEARNED FROM THE CASE STUDIES}

In this section, we discuss what we learned from the two case studies about military-civilian DV collaborations, and we list suggestions for improving collaboration based on both our interviewees and on our own observations. While recommendations from the DTFDV may not have been originally offered in the context of military-civilian collaboration, we note those that are relevant to the lessons learned about DV collaboration and comment on how they are playing out in the implementation at these two sites.

The following lessons emerged from our case studies:

- Collaborative relationships can be strengthened through formalized memorandums of understanding (MOUs).

- Civilian-military liaison positions can facilitate collaboration.

- DV collaborations can benefit when viewed as a high priority by both high-level military commands and civilian authorities.

- Payment should not be seen as a barrier to participation in civilian batterer intervention programs for military personnel who are required to attend.

- Materials that explain available installation services and victims' rights within the military would be helpful.

- Information about the military implications of the federal gun control law might reduce confusion and inconsistency.

- Formal procedures for civilians to identify DV cases and notify the military can promote informationsharing.

- Agreements are needed to address victim confidentiality.

- Benefits can emerge from collaboration conferences on DV and participation of both military and civilian representatives in DV council meetings.

- Training may be needed for both civilian and military personnel on DV and the role of collaboration.

- Working through issues arising on installations with shared civilian-military jurisdiction may require special attention.
We discuss each of these lessons in more detail below. They are not arranged in any particular order because, based on our limited and noncomprehensive case studies, we are not prepared to assign an order of priority to these issues.

\section{Collaborative relationships can be strengthened} through formalized memorandums of understanding (MOUs). If collaborative relationships between installations and civilian communities are to be maintained, it is important for them to be supported by formal agreements. This was the motivation behind the DTFDV recommendation that the DoD direct installation commanders to seek MOUs with neighboring civilian communities. According to our interviewees, the DoD grants served to facilitate more-formal collaborative agreements in both San Diego and Anchorage. For example, the DV council in Anchorage was in the process of updating its MOU for all participating organizations, which describes a general agreement to work together on DV issues. Overall, the development of DV MOUs appeared to be in the early stages and tended to be general in nature (e.g., an agreement to cooperate on DV cases but without specifics about the obligations of each party signing the MOU).

We concur with the DTFDV that developing MOUs between civilian agencies and military installations is important to institutionalizing collaborative relationships. Most of our interviewees noted that existing relationships had begun informally, with a particular individual laying the groundwork for collaboration between the military and civilian law enforcement, courts, and service providers. However, high turnover among both the military and civilian personnel may put these informal collaborations in jeopardy.

Uniformly, interviewees felt that collaborative relationships needed to be formalized so that they would not depend on individual personalities or relationships. Formal agreements were seen as important to protecting key features of the collaboration and promoting continuity over time. At the same time, some civilian interviewees cautioned that a lack of specificity about responsibilities in MOUs can create misunderstandings and tensions that can threaten collaborative relationships. They observed that successful collaborations were founded on clear mutual expectations and that formal MOUs should seek to detail those expectations. Thus, they recommended that other locations developing MOUs should work toward agreements that spell out in detail the duties of both sides and thus reduce the opportunity for differing interpretations.

Civilian-military liaison positions can facilitate collaboration. The DTFDV recommended that the DoD create a community liaison position (called a Domestic Violence Response Coordinator) at all large military 
installations. The duties for such a position include serving as a single point of contact for civilian agencies, distributing information to civilian communities about installation services, serving as a military representative on local DV councils, providing information on installations about community services, and working with military commands to forge MOUs with neighboring communities. 10

Both San Diego and Anchorage had individuals filling such roles, and our military and civilian interviewees universally saw these full-time positions as vital to the formation of successful collaborations. In San Diego in 2002, a formal military liaison position was established through the DoD incentive grant. This liaison's role is not only to provide resource and referral information to military DV victims (either service members or intimate partners of service members) identified by civilians but also to serve as a connection between civilian authorities and service providers and the neighboring military installations. In Anchorage, the collaborative role was originally established in 1999 through a victim advocate position at Fort Richardson. This victim advocate not only works directly with DV victims on the installation but also forms and strengthens collaborative relationships with the Anchorage community. This involves reaching out to civilian agencies to provide information about military procedures and services and organizing joint civilian and military training. This victim advocate initially served as a point of contact for civilians with both neighboring installations, but Elmendorf Air Force Base later added its own community liaison position to fill this role.

Based upon our limited observations in the two case study communities, we concur with DTFDV's recommendation for creating a liaison position at large installations. Our concern, however, is that the DoD and/or the military services will need to determine the size of installations that warrant a position. This is a difficult issue that must balance the goals of forming collaborative relationships against the realities of available resources. This challenge may be one reason why, in its response to Congress, the DoD reported that it would study this recommendation further.

Based on our limited case studies, we cannot offer suggestions as to the appropriate installation size for a liaison position, but we can offer an alternative model for installations deemed to be too small to support such a position. The DTFDV also recommended that each military service establish a victim advocate program consisting of trained individuals who could provide victim advocacy services for installations. Although it outlined different models for structuring the advocate position, all included providing direct services to victims. In our Anchorage case study, we observed a victim advocate position that appeared to successfully integrate a liaison component along with advocacy services. For smaller installations that may not qualify for a community liaison position, we suggest that the DoD consider expanding the victim advocate position described by the DTFDV to include a liaison component.

We caution, however, that assigning a single victim advocate the role of forming and maintaining relationships with a large number of civilian agencies and providing direct victim services may be unrealistic. As a result, some portion of the duties may be neglected. Therefore, the size of the neighboring community and the potential victim caseload should be a consideration in adopting this model. Moreover, the qualifications for such a combined military liaison/advocate position might be difficult to find in a single individual. In its description, the DTFDV emphasized that for the victim advocate position "previous experience in working with adult DV victims is invaluable as is work experience with the military."11 Although we concur with the DTFDV on this point, these requirements may be already difficult to fill in smaller communities and the addition of liaison duties may present an even greater challenge to locating qualified individuals.

For installations large enough to accommodate a community liaison position, we suggest that the DoD consider a model that would pair the victim advocate position with the community liaison position. Such a pairing would likely make it easier to satisfactorily fill the positions because extensive DV knowledge and experience would not need to be weighed against extensive military knowledge, as would be required if this position were filled by a single individual. However, each person would need some knowledge of the other's area to promote teamwork and understanding of steps necessary both to ensure victim safety and to meet legitimate military goals.

DV collaborations can benefit when viewed as a high priority of both high-level military commands and civilian authorities. Forming and maintaining DV collaborative relationships are not simple matters and require ongoing commitment of personnel and resources. Our case study interviewees agreed that those in positions of authority within the civilian communities and military installations must provide their full support to ensure that these relationships take hold and develop.

In civilian communities, identifying a single key authority position as the most important figure to provide this support is impossible because multiple agencies at multiple levels of government (city, county, state) play important roles in DV response. Also, nongovernmental organizations (such as victim advocacy organizations, medical providers, and business groups) play key roles. 
Thus, there is no clear strategy for motivating these diverse civilian organizations to work together to seek collaborative relationships with military installations.

A possible strategy is the establishment of a funding source to promote military-civilian collaboration. Similar incentive grants promoting collaboration among civilian agencies, such as those offered through the Federal Violence Against Women Office (VAWO), have substantially contributed to forming DV collaborations in civilian communities across the country. In fact, the DTFDV recommended that VAWO create such an incentive program to encourage civilian communities to build DV collaborations with military installations. We second this recommendation and anticipate that an incentive program targeted specifically toward these collaborations would provide a catalyst for individuals in key positions of authority in civilian agencies to support these relationships. Such an incentive program could also provide resources for testing of innovative ideas in communities that have already established some level of collaboration with neighboring installations.

Compared with civilian communities, it is far easier to identify the key local military authority figure whose support is necessary for developing successful collaborative relationships. The installation commander serves as the key local decisionmaker and sets the standards for individuals at all lower levels of command. Regardless of the level of established collaboration, our military interviewees asserted that commitment to forming and maintaining these relationships is likely to vary as new officers rotate into installation command positions. They felt that, for DV collaborations to be given initial and consistent support, the DoD should consider issuing a directive to the military services that DV is a preparedness issue (i.e., an issue that affects service members' ability to perform their duties) and that building collaborations with civilian communities should be a command priority. This would encourage both existing and new installation commanders to emphasize the message that DV will not be tolerated and to provide the leadership and resources necessary for establishing and maintaining collaborative relationships.

The DTFDV recommended that the DoD encourage commanding officers at every level to assert and reinforce in briefings, public addresses to service members, and other venues that DV negatively affects the military morale and readiness of service members to perform their mission. 12 Based upon our case studies, we agree but would also suggest that it is important for commanders to communicate to the civilian community that DV will not be tolerated and that it is a priority for the military to address. This message can go a long way toward encouraging civilians to approach installations with ideas for collaboration and to welcome invitations from installations to join them in collaborative relationships.
Anchorage interviewees illustrated this point with the following example. A high-level military commander from each of the neighboring military installations joined the mayor of Anchorage in taping a televised public service announcement describing DV as an issue taken very seriously by both the military and the civilian community. As one military commander noted, this sort of message communicates to service members that they cannot expect to hide abusive behavior from the military by living offinstallation in the surrounding community.

Payment should not be seen as a barrier to participation in civilian batterer intervention programs for military personnel required by civilian judges or prosecutors to attend. When domestic incidents occur within the civilian jurisdiction, under some circumstances (primarily a DV conviction or agreement to participate to avoid prosecution), military personnel may be required to attend a civilian batterer intervention program. Our interviewees explained that civilian batterer intervention programs tend to be longer than military programs. For example, our San Diego interviewees stated that batterers are required to attend a 52-week intervention program. Anchorage interviewees noted that the state requirement for batterer intervention programs is 36 weeks. In comparison, the military's programs for batterers were 24-26 weeks at one installation and 12 weeks at another. 13

According to our interviewees, payment for civilian programs, unlike programs offered by the installation, often falls to the service member because military benefits do not cover civilian programs. For victims who share finances with abusers, payments for such programs can result in a drain on family budgets and, thus, in a sort of penalty to the victim. This can be the case whether the abuser is a civilian or a service member. Some of our civilian interviewees noted that for incidents involving service members this concern can result in pressure on civilians to allow installation programs to substitute for the more intensive civilian programs, even when they believe the civilian model is more appropriate in a particular case. We suggest that awareness training for military commanders and other military personnel would be helpful to make it clear that payment should not be a consideration in negotiations between civilians and the military about what might be the best strategy for handling a particular case.

Materials that explain available installation services and victim's rights within the military would be helpful. Our interviews with both civilian and military interviewees called attention to the need for educational materials for military spouses about the services available to them and their rights within the military should they become victims of DV. Civilian interviewees, including service providers, victim advocates, legal services, and criminal justice professionals, also reported that they were unfamiliar with victims' rights and available installation services 
and would find the information useful when interacting with victims. Several of our interviewees noted that this information is vital to collaboration because information about victims' rights and protections can assist civilians in allaying victims' fears about the negative consequences of notifying installations about DV incidents.

For example, victims may fear that a DV incident will negatively impact a military spouse's career (either through termination or demotion), resulting in a loss of pay, housing, and medical and other benefits. The interviewees noted that such fears are often compounded by victims' misperceptions-service member spouses may serve as the sole source of information about victim rights and protections. Abusive spouses may exaggerate or distort the potential consequences for victims and/or the family if military commanders are notified of DV incidents. Thus, the development of educational materials addressing these issues could assist civilians in working with victims of DV and collaborating on these cases with neighboring installations.

In discussing victim safety in its 2001 annual report, the DTFDV also saw the need to educate new military spouses about available DV installation services. It noted that a substantial minority of military spouses who acknowledged abuse did not know how to get help from the military, despite outreach efforts by the FAP. Thus, the DTFDV recommended that the DoD provide written information on the services available to family members on local installations, including

- a statement from the Secretary of Defense on the DoD's commitment to victim safety

- specific details about the FAP, such as contact information and confidentiality issues

- military orders of protection

- the Transitional Compensation Program 14

- other installation-specific information as appropriate

- specific information on the National Domestic Violence Hotline

- local community resources and the process for obtaining civilian protection orders. 15

We concur with the DTFDV on this recommendation and further suggest that such DV materials contain information oriented toward civilian spouses (not service providers) about rights and protections within the military and that these materials be widely distributed to the surrounding civilian community. This information should be tailored differently for installations within the continental United States (CONUS) and for those in Alaska and Hawaii because some different rules may apply.

The DTFDV also recommended that military DV service information be part of the "welcome package" that new military spouses receive in the process of obtaining their family member identification card. In addition to new spouses, we suggest that materials on victim services and rights be a routine part of the orientation for all military families upon transferring to a new military installation. We also suggest that the materials include specific information on civilian DV services, programs, and protection available in the local community. Our civilian interviewees recommended that installations invite civilian representatives to participate in these orientations to help reinforce the message that community resources are also available to military spouses. Because these orientation sessions for family members most often occur without the presence of the military service member, we agree that this would be an ideal opportunity to pass on both military and civilian DV-related information.

Information about the military implications of the federal gun control law might reduce confusion and inconsistency. One area of confusion in the military's response to DV that we noted in both our military and civilian interviews centered on the removal of firearms from service members in DV cases. ${ }^{16}$ Federal gun control law forbids individuals (including military service members) from possessing firearms following conviction for a DV misdemeanor crime or issuance of a DV protection order that meets certain standards. 17 There was inconsistency in responses by both military and civilian interviewees about whether (on a given installation) a firearm would be removed by military authorities following notification of the existence of a DV protection order or misdemeanor conviction. Some indicated that this practice was automatic; others stated that it would not occur unless a weapon had been used as part of the DV incident. One military commander stated that he was aware of the federal gun law related to DV but was not aware of whether those under his command were removing firearms. Some interviewees noted that this was not only a problem with the military. There was also variation in the enforcement of the federal gun control law by civilian authorities.

Moreover, we received inconsistent responses from military interviewees in different services about whether firearm removal would spell the end of a military career. Some indicated that it would result in certain discharge; others indicated that accommodation would be possible on a case-by-case basis. Inconsistency in removal of firearms and confusion over the potential career implications led to concern among some of our civilian interviewees about the unpredictability of the military response. Dissemination of information about the implications of the federal gun control law on firearm removal and career implications would strengthen collaborative relationships because it would allow civilians to predict more accurately the potential victim safety implications of a DV conviction or protection order. For example, the victim's safety may be jeopardized both by the abuser's access to a firearm and 
by the removal of a firearm accompanied by the threat of career termination. The development of a consistent policy and response would allow agreements to be established between civilian agencies and neighboring installations about how to jointly address these potential threats to victim safety.

The DTFDV observed that the DoD does not mandate awareness training for commanders and that many were not aware of the existence of the federal gun control law. 18 The DTFDV recommended that the DoD conduct an awareness campaign to fully inform the military community about the federal law and its consequences. Based on our case study observations, we concur with the DTFDV that awareness training by the services seems important in developing a consistent response to this issue. We would add that the civilian community (including law enforcement officers, prosecutors, and service providers) should also be provided information about the implications of the federal law for military service members, to reduce the unpredictability of response and promote opportunities for joint civilian-military planning for victim safety.

Formal procedures for civilians to identify DV cases and notify the military can promote informationsharing. For military installations and civilian communities to work collaboratively, there must be some method of determining when one or both parties to a DV incident is a service member. If these incidents occur on installations, identification of service members is not an issue. In the civilian community, however, military affiliation may not be discovered, and military commanders may not be notified of an arrest, prosecution, or even conviction.

This lack of knowledge hinders domestic violence collaboration. Military commanders can assist civilian communities in a variety of ways in holding abusers accountable for their behavior. Because the majority of abusers are service members and their victims are civilian intimate partners, our interviewees noted that commanders can play a key role in helping to ensure that abusers make all court appearances; can provide information helpful in the investigation and prosecution of cases; can impose additional military sanctions as appropriate; and can ensure that defendants complete sentencing requirements such as participation in a batterer intervention program. For example, one civilian prosecutor informed us that service members may fabricate military excuses (deployment, training exercises, etc.) for their failure to comply with requirements and that contact with the military command can be vital in verifying these defendant claims. Because service members are transferred frequently to new installations, commanders can ensure that information about DV incidents is passed on to the receiving installation and that transfers do not interfere with service members' completing any outstanding obligations.
Moreover, military commanders can reinforce the conditions of a civilian order of protection by issuing a nocontact order or a Military Order of Protection (MOP). Under these conditions, our military interviewees noted that if a service member violates the no-contact provisions of a civilian order of protection, he or she will have also violated a command order and thus be subject to military discipline. Commanders can also have an important role in addressing any fears or misperceptions abused civilian spouses may have as to how a DV incident might affect their means of support.

According to our case studies, it is often challenging for civilian law enforcement to identify military service members when responding to DV calls and making arrests, because these individuals will often try to hide their military affiliation to avoid notification of the installation. Law enforcement interviewees in both Anchorage and San Diego stated that police are neither specifically directed to seek to identify service members nor trained in strategies for doing so. Despite this, they stated that police often note in their reports when they discover a military affiliation for either party. If neither the suspect nor the victim discloses a military affiliation, civilian police may draw on their own previous military experience or learn from colleagues signs that might suggest a military affiliation. According to our interviewees, these clues include an individual's appearance and mannerisms, presence of military decals on the automobile or paraphernalia in the home, location of a residence in an area where military families are concentrated, and information disclosed in interviews with neighbors or other family members.

Once civilian law enforcement personnel have identified a military affiliation, they face the challenge of finding a way to efficiently communicate this information to the appropriate military authorities. Anchorage and San Diego have adopted different approaches.

Notification of the Military in San Diego. San Diego has no system for notifying installations of a service member's involvement in a DV call if an arrest does not occur. In the case of an arrest, a process has been established for identifying service members. On a regular basis (every 2-3 days), the neighboring military installations dispatch military law enforcement personnel to review civilian arrest records. Called "court liaisons," these military law enforcement personnel screen all paper arrest records in search of indications that a suspect may be a service member. The police reports do not contain a designated box to check indicating a military affiliation. Typically, military affiliation may be identified when the "suspect's employer" line on arrest reports lists the name of a military installation. The court liaisons also use other strategies such as reviewing police narratives for suggestions of military affiliations and looking for telephone number prefixes used by the neighboring installations. Confirmation of a 
service member's identity is achieved through a search of military personnel rosters.

Once an arrested service member has been identified, the military court liaisons notify the respective military commands about the arrest charge, release date, and upcoming court dates. Court appearances are monitored through the use of a military sign-in roster. The court liaison also will notify the command if a warrant for failure to appear in court has been issued. If requested by the command, the court liaison also will attend the court hearing and inform the commander about the outcome and legal requirements imposed. The military court liaison process does not include notifying commands about the issuance of protection orders but does include notifying them about violation of protection orders if the violation results in an arrest. One installation is currently working on a system of protection order notification, but this is still in the formative stages.

Aside from the military court liaison process, there is no other process of notification directly from civilian agencies to military commands about court dates or case outcomes.

Notification of the Military in Anchorage. Anchorage has no formal mechanism for notification of DV incidents and arrests, but a civilian APD officer or supervisor may call a military commander about a specific case. If a commander learns about an arrest through some other method, a military official may call APD directly to obtain information about the arrest.

As in San Diego, APD arrest reports do not contain a special place for police to indicate a suspect's military affiliation. Recently, APD has been exploring the possibility of regularly providing a list of all arrested individuals to the neighboring installations for comparison with military personnel rosters. To date, this is not being done because of lack of personnel to produce the weekly reports. Likewise, there is no formal process for notifying the installation of court dates, case outcomes, and sentencing requirements, but military authorities may be contacted on a case-by-case basis. The civilian court also has no formal system for notifying the military about the issuance of civilian protection orders. Because a large number of protection orders are issued annually, our civilian court interviewees reported that it would presently be too labor-intensive to identify orders involving service members and to notify the respective commands. There is, however, an informal agreement in process wherein the courts would make available to the installations a list of all protection orders issued on daily basis. The installations could then check this list against military personnel rosters. Turnover among the civilian court clerks has slowed the implementation of this agreement, but it is expected to be in place soon.
From our observations, the military court liaison program established in San Diego appears to be a promising strategy for providing arrest notification, but it has areas that need to be improved if it is to represent a model for other locations. The program in San Diego primarily relies on the military to implement it, with little active assistance from law enforcement. In addition, military interviewees noted that the process of manually sorting through arrest reports is time-consuming and labor-intensive. Civilian law enforcement could greatly facilitate the process by training police officers to actively identify service members in DV incidents and by adding a clearly designated location (e.g., a check box) on incident and arrest reports indicating the presence of a military affiliation. Although creating an automated system of arrest notification in DV cases may be potentially costly particularly in the developmental stages, doing so would make the process much more efficient.

In addition, the military needs to be informed about sentencing orders or prosecutorial diversion requirements to ensure that service members are not deployed or required to participate in remote training that might interfere with DV intervention programs, court appearances, or other requirements.

Like the DTFDV, we found in our case study interviews that military commands may be unaware of the existence of a civilian order of protection. When the military command is aware of such an order, it can help with enforcement and could issue a military protection order to back up the civilian order of protection. ${ }^{19}$ Thus, we suggest that civilian courts consider developing procedures for identifying DV protection orders involving service members and for notifying the military command of these orders.

Finally, we also suggest that the DoD and/or the military services consider issuing a directive that makes it the responsibility of service members to report to a specified authority if they have been arrested for DV in the civilian community or are the subject of a DV protection order. Such a directive would also allow the application of military sanctions for service members who withhold this information from the command. This requirement may increase the likelihood that service members would disclose arrests and protection orders and would thus enable commanders to reinforce the efforts of civilian communities to ensure victim safety and hold abusers accountable for their behavior.

Agreements are needed to address victim confidentiality. One area of difference between the military and civilian approaches to DV that our case studies identified is victim confidentiality. According to our civilian victim advocate interviewees, preventing the disclosure of the identity of victims seeking services is of paramount con- 
cern. Civilian advocates allow victims to determine to whom their abuse is disclosed. According to our military interviewees, the military views DV as an issue that may affect the ability of service members to focus completely on their mission and thus their fitness for duty. It is therefore vital that commanders be made aware of DV incidents, regardless of the victim's wishes. Our civilian and some military interviewees expressed concern that this lack of confidentiality may discourage civilian service providers from referring victims to FAP services and discourage both abusers and victims from seeking FAP services on their own.

In the communities we visited, sharing information about arrests that occur in the civilian community was nearly universally seen as a positive step. This notification does compromise confidentiality because when the military command is notified that a specific service member is involved in a DV incident, the identity of the victim is easily deduced, at least in the case of a married service member. From our interviews with civilian service providers, we learned that although non-service member victims were not particularly concerned about the disclosure of their identity per se, they were concerned about the impact disclosure of DV would have on their relationship and on the abuser's career, income, and family military benefits. Thus, the disclosure of a service member's arrest would trigger the fears of married victims regardless of whether the commanding officer was informed of the victim's identity. ${ }^{20}$

Civilian DV service providers we interviewed felt that despite victims' fears, command notification of arrest was still important because military commanders can have a significant role in protecting the victims. However, they felt this notification could only be justified if commanders were trained to respond to DV with victim safety and abuser accountability as their primary goals.

Based upon our observations, we share these views and suggest that, despite victim confidentiality concerns, civilian communities develop strategies for notifying neighboring military installations of arrests and protection orders. Moreover, we suggest that the DoD consider supporting these efforts by providing military personnel to facilitate this notification, such as the military court liaison positions in the San Diego area. Military personnel, however, informed us that the court liaison position was not seen as a career-enhancing role because there was no specific billet designated for this position. The DoD or the military services could support civilian notification efforts by creating such a billet to add career value to such a position. This position should be separate and distinct from a victim advocate position.

For cases in the civilian community where arrests do not result, where protection orders are issued by a civilian court, or where victims seek DV services from civilian agencies, we suggest that agreements be drafted about sharing information between civilian communities and military installations. Despite their apparent importance for collaborative relationships, these agreements may be difficult to forge because of the direct conflict between the civilian concern for victim confidentiality and the military concern for complete information about DV in service members' families.

Recommendations by the DTFDV, if implemented by the DoD, may help address this area of potential civilianmilitary conflict. The DTFDV urged the DoD to develop a nondisclosure policy that would "provide confidentiality to victims of domestic violence who seek to receive support, information, options, and resources to address the violence in their lives." 21 This proposed nondisclosure policy would apply only to military victim advocates. Based upon our case study interviews, we concur with this recommendation. Although the DTFDV did not make this recommendation in the context of collaboration, it may also help collaborative relationships if civilian victim advocates have military counterparts to whom they could refer victims for military-specific support and services without triggering victim fears about notifying the command.

Benefits can emerge from collaboration conferences on DV and the participation of both military and civilian representatives in DV council meetings. According to our case studies, the most widely endorsed strategies for developing and strengthening DV collaboration are regular participation of both military and civilian representatives in DV council meetings and collaboration conferences.

DV Council Meetings. In both Anchorage and San Diego, representatives of neighboring installations and civilian agencies interact regularly at monthly DV council meetings. Our interviewees stated that these regular meetings are vital for collaborative relationships because they allow opportunities for

- forming relationships between individuals that can serve as points of contact within both military and civilian organizations

- increasing understanding about the respective roles of various installation components and civilian agencies in responding to DV cases

- presenting information on policies and practices that simultaneously reach key representatives of both military and civilian agencies

- providing updates about staff turnover and program and policy changes

- enabling immediate problem-solving, such as review of practices that may be problematic for collaboration, and fostering discussion of potential solutions 
- promoting the formation of the formal collaborative relationships specified in MOUs.

Based on our observations, we suggest that localities interested in forming military-civilian collaborations consider DV councils as a mechanism for fostering such relationships. In communities where civilian DV councils exist but military representatives do not attend, we suggest that civilian representatives invite neighboring military installations to participate. Such invitations should be made broadly and should include installation commanders as well as those involved in FAP programs, military law enforcement, and military community service programs. For installations in communities where no DV council (or other multiagency planning body that may cover DV) exists, installation commanders could contribute to establishing these bodies by organizing initial collaboration meetings and inviting directors of civilian agencies, such as criminal justice agencies and victim services organizations.

Local Collaboration Conferences. In both San Diego and Anchorage, local conferences had taken place that focus on forming and strengthening DV collaboration between military installations and civilian communities. In San Diego, an annual conference, called Partners in Peace, is sponsored by Navy Region Southwest and takes place on the installation. In Anchorage, the DoD grant provided funds for a first-ever conference in March 2003, which took place in downtown Anchorage. These conferences brought together a large number of individuals (including multiple staff members from the same organization) and included military components and civilian agencies that may not participate in the DV council meetings. The Anchorage conference also featured presentations by representatives from other communities (including San Diego) who offered insights based on their experience with military-civilian collaboration. Both our military and civilian interviewees found these presentations valuable because they inspired ideas for local innovation and reduced the discouragement that often results from the seemingly slow pace of relationship-building.

The interviewees also saw collaboration conferences as playing an important role in emphasizing the importance of the DV issue both to the military and to the civilian communities. In Anchorage, in particular, the civilian interviewees saw the local conference as the single most important catalyst for collaboration with the military. It gave both civilians and military personnel a wealth of education; afforded numerous opportunities for individual networking; and provided a symbol of the formal beginning of new collaboration efforts in the Anchorage area.

Most military and civilian interviewees commented that collaboration conferences should not be a one-time event. Regular local conferences were seen as key to keep- ing DV collaboration on the "front burner" of both the military and civilian community. They create networking opportunities, particularly for new staff, and allow ongoing, efficient educational opportunities for large numbers of personnel.

Although it might be considerably less costly for the DoD or other funder (such as VAWO) to host national or regional collaboration conferences, our observations lead us to conclude that they cannot substitute for local conferences, for two key reasons. First, conferences that require more than local travel are not likely to be well attended by both military and civilian representatives. Moreover, if funding is provided for travel, it is likely to cover only one or a very small number of staff members from a single organization, who may not be well equipped to educate their colleagues about the lessons learned at the national conference. A local conference is likely to be attended by a large number of staff, particularly if civilian agency directors and military commanders make attendance a priority. Second, distant conferences cannot provide local networking opportunities or specific information about local practices and procedures. According to our case study interviewees, the greatest value of the local conferences lies in establishing collaboration and bringing new community partners into existing collaborations.

We suggest that local collaboration conferences be considered in other localities and be established as annual or semiannual events to provide updated information, maintain contacts with existing and new personnel (both military and civilian), and underscore that collaboration does not end with signing an MOU but is an ongoing relationship that must be maintained. A key consideration in establishing and maintaining these local conferences is locating an adequate funding source. One possibility is that funding could be shared by VAWO and the DoD. In some areas, local private foundations and state or local government funds also might be tapped to assist with expenses. There is still considerable value in national and regional collaboration conferences, particularly for highlighting innovative practices developed in some areas that can serve as models for others. Thus, we suggest that DoD and/or VAWO consider establishing a source of funding to support these conferences as well.

Training may be needed for both civilian and military personnel on DV and the role of collaboration.

According to our case study interviews, adequate training about the potential partner's orientation toward DV, organizational structures, and roles and responsibilities of organizational units/agencies that handle DV cases is vital to promoting collaboration between civilian communities and neighboring installations.

Military Training. Our civilian interviewees noted variation within installations with respect to the amount of 
emphasis commanders place on DV and their response to DV cases. Individual commanders have considerable discretion about how to handle such cases and may take steps ranging from nothing at all to drastic consequences (such as demotion or dismissal) that could jeopardize a victim's sole means of support. Civilian interviewees noted occasional problems with commanders intervening on behalf of an abuser while appearing to disregard victim safety. Such variation leaves civilian service providers uncertain as to whether referral to a military program would be potentially helpful or harmful to their clients.

Several civilian interviewees explained that the inconsistency in command response was due to a lack of training about the seriousness and complexity of DV. This can lead commanders to doubt whether a victim's claims about abuse are legitimate if the accused service member is an otherwise exemplary soldier. They noted that commanders often lack incentive for holding service members accountable for even well-documented abusive behavior because such actions can jeopardize the career of an otherwise valuable member of the military workforce. Several interviewees noted that this lack of training is compounded by a lack of clear standards for and monitoring of the handling of domestic violence cases by commanders at all levels of the military.

We suggest that the $\mathrm{DoD}$ consider exploring these issues. The DTFDV recommended (although not in the context of collaboration) that commanders at all levels should receive training on DV in general and appropriate strategies for responding to such cases.22 Based upon our observations, it appears that such training could help support the formation and maintenance of collaborative relationships with civilian communities. A few interviewees noted that training on standards for handling cases would not be adequate by itself; a system for monitoring command compliance with these standards would also be necessary to reduce inconsistency in command response. We suggest that the DoD consider developing such a system.

Civilian Training. Military personnel may be unfamiliar with the requirements and practices that operate in the civilian community, but difficulties also arise when civilians are unfamiliar with military procedures and organization. Many civilian interviewees noted that they know little about how the military works and what services it provides. Each installation contains multiple commands at varying levels, and identifying the appropriate military supervisor for an individual service member (or even a place to start) can be a particular problem for civilians. This problem can be compounded by the need for immediate measures to ensure victim safety that DV cases often involve. Civilian interviewees also stated that it can be difficult to determine whether military-related excuses for failure to comply with prosecutor agreements or sentenc- ing requirements are legitimate. For example, defendants may claim that they are being deployed and therefore unable to complete an intervention program. Civilians may be uncertain about whom to contact at an installation to verify this information. Civilian interviewees expressed a need to know more about military chains of command, where to direct requests for information, and where to direct urgent requests, in particular.

A related problem is that civilians also tend to be unfamiliar with military terminology, rank structure, and rank designations on uniforms. Civilian interviewees noted that when they are contacted by phone or in person by uniformed military personnel about a DV case involving another service member, it is difficult to know whether that individual has the authority to speak for the military command. Civilians who are former members of the armed forces have a considerable advantage in this regard and may serve as a resource for colleagues in assessing these situations. For example, one civilian prosecutor informed us that military defendants have occasionally appeared with a soldier in a uniform displaying the same rank who claimed to be a superior officer. Previous military experience allows the prosecutor to recognize such deceptions and avoid making concessions based on commitments made by an illegitimate authority figure.

In addition, several civilian service providers indicated a need for more information about the types of services provided for victims and abusers by neighboring installations so they can assess when referrals to installation services may be appropriate in particular cases. Many social service providers expressed hesitation to make referrals, particularly referrals of victims, to the FAP and other installation programs without more information about what these services might consist of and how they compare with those offered within the community.

The DTFDV did not address military training for civilian communities; however, it is also vital in forming successful collaboration. Thus, we suggest that the military provide training for civilian criminal justice, batterer intervention, and victim service agencies about the organizational structure, available programs, and procedures of their military counterparts. In addition to, or as part of, such training, our civilian interviewees expressed an interest in being invited to visit installations to increase their comfort level with the military and to demystify neighboring installations.

Our case studies also suggest that general information should be made available to the civilian community about the military, such as how the chain of command is structured, the meaning of terminology and acronyms used, what different uniforms and insignia represent, and a general overview of the types of services provided on the installation. 
Working through issues arising on installations having shared civilian-military jurisdiction may require special attention. In both of our case study communities, civilian authorities shared jurisdiction on one of the neighboring installations. Response to DV incidents occurring on these installations can present unique challenges.

Shared Jurisdiction in San Diego. In the San Diego area, a portion of Marine Corps Air Station Miramar containing base housing is under concurrent jurisdiction with the State of California, and SDPD provides law enforcement services there. An MOU between the SDPD and the installation established that Marine law enforcement personnel from the Provost Marshall Office (PMO) would serve in the first-responder role to incidents that occur on base. The agreement specifies that the PMO would then notify SDPD, which would assume jurisdiction. Following notification, SDPD would then assign a detective from the department's DV unit to conduct a follow-up investigation in a DV case.

According to our interviews, the involvement of both military and civilian police in a single case presents complications that require mutual understanding of procedures and active cooperation. For example, the civilian police detectives did not initially realize that military first responders produce documentation that would be important for follow-up investigations, such as incident reports, dispatch and communications logs, and tapes of the equivalent of 911 calls. Thus, education for civilian law enforcement officers about military procedures was necessary to ensure that they are able to fully investigate each case. Likewise, education of military law enforcement personnel about civilian needs is necessary to ensure that they follow procedures that lead to successful investigations and prosecutions. For example, delays by military law enforcement in responding to DV incidents and in notifying the SDPD can result in the loss of important evidence for civilian prosecution. Thus, our civilian law enforcement interviewees noted that the need for immediate action must be made a priority of military law enforcement. Unlike civilian police, military law enforcement officers are not trained to write incident reports for potential use in civilian prosecution. Consequently, our civilian interviewees noted that military police tended to write inadequately detailed reports that can hamper the investigation and prosecution of a DV case. Relatedly, military law enforcement personnel and first-level supervisors tend to lack training on DV issues in general, which can lead to misunderstandings and conflicts when they are working with highly trained civilian DV detectives.

Shared Jurisdiction in Anchorage. In the Anchorage area, Fort Richardson is under shared (or concurrent) jurisdiction with the state of Alaska. As a result, the APD provides law enforcement services on the installation in DV cases. Local arrangements for sharing jurisdiction on the installation are somewhat different from those in San Diego. The military maintains jurisdiction over DV cases that involve two service members. This however, represents a very small share of the incidents. The vast majority of cases involve a service member and a civilian family member, and these fall under the jurisdiction of APD. In the latter case, military law enforcement provides first-responder personnel and notifies APD to respond to the installation for investigation. Complications have arisen because military law enforcement personnel and supervisors lack training about the legal requirements under which APD officers work.

Specifically, Alaska law requires that police make an arrest if they have probable cause to believe a domestic violence crime has occurred. Our civilian interviewees noted that APD officers are trained to consistently enforce this law and conflict is created when military law enforcement personnel are unfamiliar with this requirement and do not believe an arrest is necessary. Another legal requirement is that civilian police arrest only the primary physical aggressor and avoid arresting a victim who may have used force in self-defense. Other conflicts have developed when military law enforcement personnel encourage civilian police to arrest or otherwise remove from the installation a civilian spouse whom APD believed to be the victim rather than primary physical aggressor. In an effort to reduce such conflicts, APD officers responding to DV incidents on base are accompanied by an APD supervisor whose role is to resolve any conflicts that may arise around these issues. A civilian APD interviewee noted that such conflicts have lessened noticeably recently and believes this is due to the increased DV training received by and commitment to collaboration by commanders at the installation.

Our case study interviews suggest that special attention is needed to address challenges to collaboration that may arise in the context of shared jurisdiction. We suggest that civilian DV service providers, victim advocates, and representatives of civilian criminal justice agencies (particularly law enforcement) conduct local training sessions for military law enforcement personnel to help increase their understanding of critical issues in DV response and of civilian practices and procedures in particular. This training could be hosted either by the civilian agencies, the military installation, or both. Because of the high turnover in military personnel, it is important that training be provided on an ongoing basis. While training of military personnel by national or state-level trainers would be helpful, it cannot substitute for information provided by representatives from local civilian communities. Because of the variation in DV laws across states and the enforcement of 
DV laws at the local level, instruction by local representatives is the best way to train personnel at neighboring installations.

\section{NEED FOR MILITARY-CIVILIAN COLLABORATION RESEARCH}

In our case study interviews, we found that none of the civilian organizations kept records in a way that would enable them to report exactly how many of their cases involved military service members. When military affiliation was noted by civilian agencies, it was not done consistently and, thus, would require manual review of case documentation. Collecting data on these cases could provide vital information for understanding case characteristics, how cases are handled, and what elements involved in processing the cases may be improved. Such data collection might also make it possible to estimate the level of both military and civilian resources invested in processing DV cases involving service members and to assess strategies for making better use of resources.

Clearly, developing a data collection strategy on DV incidents involving services members that is affordable and sustainable within current budgets will be a considerable challenge. Thus, we suggest that a pilot study be undertaken in one or several communities with large military installations to develop a methodology for data collection by civilian communities. Because of the substantial nature of the undertaking, it may be necessary to narrow the scope of the pilot study to a single civilian agency, such as law enforcement. The study could develop and pilot test methods for coding cases and tracking these cases in a way that would enable this information to be routinely collected and shared with the military. The methodology could be designed to serve as a model that may be adopted by other jurisdictions, and the study could be sponsored jointly or separately by the DoD, VAWO, or other federal funder located with the U.S. Department of Justice.

In addition to the need for descriptive data collection, there is a need for research that specifically examines potential challenges to military-civilian collaboration and identifies strategies for overcoming them. A few limited case studies, such as those presented here, can reveal some issues that might be faced in other localities, but they are far from adequate to fill the gulf in knowledge about military-civilian collaboration. Research must be undertaken in a number of localities representative of the range of collaboration experiences and community and installation characteristics. Careful consideration of the methodology for such research is necessary, but we recommend that in-person interviews of military and civilian personnel be a component of any future study. Although interviews significantly increase research costs, they offer a rich source of data and can provide an important context for the interpretation of other data sources, such as written survey responses.

The support of the DoD and the individual services for such research is vital because of the need to acquire local installation cooperation with data collection. If the cooperation of key civilian communities is to be secured (particularly in areas where DV collaborations have not been developed), researchers and/or the military may need to offer a convincing case for why participation in such research can benefit the civilian community.

We suggest that the DoD and VAWO consider partnering to invest funds in launching such a research program. Building knowledge in this area could significantly increase the DoD's chances of success in promoting local civilian-military collaborations. Moreover, this research could assess the outcomes of such collaborations and provide information on what forms of collaboration might be most effective in reducing DV incidents and promoting victim safety.

\section{ENDNOTES}

1 Defense Task Force on Domestic Violence, Third Year Report. Arlington, Va.: DTFDV, 2003. The final 2003 report contained an additional 13 recommendations, but as of this writing the Secretary of Defense's response to these recommendations has not yet been submitted to Congress.

2 Although some of the recommendations we identified in the DTFDV's three annual reports are explicitly intended to encourage or enable collaboration, based upon our case study findings we also identified others that are relevant to implementing collaboration.

3 We contacted the DoD's Public Information Office, the DoD's Criminal Investigation Office, and the criminal investigation office-equivalent for each service. We were informed that jurisdiction type was not recorded or tabulated by these offices and it would be necessary to contact each installation to ascertain its jurisdiction type(s).

4 R. Blanchard, Protecting Children in Military Families: A Cooperative Response, Washington, D.C.: U.S. Department of Health and Human Services, 1992.

5 Military Family Resource Center, Implementation of Department of Defense Child and Spouse Abuse Programs in Areas of Exclusive Federal Jurisdiction, Arlington, Va.: Military Family Resource Center, Office of the Assistant Secretary of Defense for Force Management and Personnel, 1986.

6 In fiscal year 2000, the DoD established the Incentive Program for Improving Responses to Domestic Violence, which provides funding on a competitive basis to installations seeking to establish or enhance domestic violence coordination internally, with other installations, and with civilian agencies. 
7 In the 2000 U.S. Census, the San Diego population was 1,223,400. The number of active-duty members stationed at the three neighboring installations was 44,201, according the Fiscal Year 2002 DoD Base Structure Report. For the city of Anchorage, the population was 260,283 in the 2000 Census, with 9,240 active-duty members stationed at the neighboring two installations.

8 In Anchorage, this body is called the Domestic Violence Caucus, but we use the term "domestic violence council" because consistency in terminology will aid in discussion of our collective findings.

9 The installation-based FAP is the primary organization unit within the military for responding to domestic violence. FAP personnel are either social workers, marriage and family therapists, or psychologists who investigate reports of abuse and assess whether these reports can be substantiated. FAPs also provide ongoing assessment and programming to address DV in military families.

10 Defense Task Force on Domestic Violence, Second Year Report, Arlington, Va.: DTFDV, 2002, p. 28.

11 DTFDV, Third Year Report, pp. 26-27.

12 DTFDV, Third Year Report.

13 We did not evaluate the research literature on the effectiveness of batterer intervention programs, which was beyond the scope of this study. In this report, we are simply calling attention to differences between the civilian and military models.

14 The Transitional Compensation Program provides a minimum of 12 months of support for victims whose active-duty spouse was discharged from the military for DV.

15 Defense Task Force on Domestic Violence, First Year Report, Arlington, Va.: DTFDV, 2001, pp. 77-78.
16 Possession of a firearm for military job-related reasons can range between purposes that are related to training or combat-which are temporary, closely supervised, and generally remote from victimsto purposes related to military law enforcement personnel, who are supervised but with more freedom of movement. In addition, some military members may possess a personal firearm.

17 According to the DTFDV, the Lautenberg Amendment (18 U.S.C., Section 922) to the Gun Control Act of 1968 makes it unlawful for any person convicted of a "misdemeanor crime of domestic violence" or who is the subject of a qualifying protection order to ship, transport, possess, or receive firearms or ammunition. The statute defines this as being an offense that (a) is a misdemeanor under federal or state law; (b) has as an element the use or attempted use of physical force, or the threatened use of a deadly weapon, committed by a current or former spouse, parent, or guardian of the victim; by a person with whom the victim shares a child in common; by a person who is cohabiting with or who has cohabited with the victim as a spouse, parent, or guardian; or by a person similarly situated to a spouse, parent, or guardian of the victim.

18 DTFDV, First Year Report, pp. 41-42.

19 Indeed, one of the DTFDV recommendations was that the DoD take actions to make violations of a civilian order of protection an offense under the Uniform Code of Military Justice (DTFDV, First Year Report, p. 25).

20 In this report, we have touched upon a number of extremely complex confidentiality issues. A complete review of the issue of confidentiality for domestic violence cases is beyond the scope of this study.

21 DTFDV, Third Year Report, p. 121.

22 DTFDV, Third Year Report. 
This research in the public interest was supported by RAND, using discretionary funds made possible by the generosity of RAND's donors, the fees earned on client-funded research, and independent research and development (IRED) funds provided by the Department of Defense. A related issue paper (Formalizing Collaboration: Establishing Domestic Violence Memorandums of Understanding Between Military Installations and Civilian Communities) is available at www.rand.org/publications/IP/IP254/. RAND is a nonprofit institution that helps improve policy and decisionmaking through research and analysis. Results of specific studies are documented in other RAND publications and in professional journal articles and books. To obtain information about RAND studies or to order documents, contact Distribution Services (Telephone: 310-451-7002; toll free 877-584-8642; FAX: 310-451-6915; or email: order@rand.org). Abstracts of RAND documents may be viewed at www.rand.org. RAND ${ }^{\circledR}$ is a registered trademark.

\section{RAND}

1700 Main Street, P.O. Box 2138, Santa Monica, California 90407-2138 • Telephone 310-393-0411 • FAX 310-393-4818 1200 South Hayes Street, Arlington, Virginia 22202-5050 • Telephone 703-413-1100 • FAX 703-413-8111

201 North Craig Street, Suite 202, Pittsburgh, Pennsylvania 15213-1516 • Telephone 412-683-2300 • FAX 412-683-2800 